\title{
DO CORPO AO \\ DESEJO: UM OLHAR SOBRE O SUJEITO ${ }^{1}$
}

\section{Gislene Jardim}

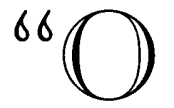

senhor, por exemplo, que sabe e estuda, suponho nem tenha idéia do que seja na verdadeum espelho? Demais, decerto, das noções de fisica, com que se familiarizou, as leis da óptica. Reportome ao transcendente. Eudo, aliás, é a ponta de um mistério. Onclusive, os fatos. Ou a ausência deles. Duvida? Uando nada acontece, há um milagre que não estamos vendo.

( João Guimarães Rosa - O Espelho in Primeiras Estórias) 
Existem crianças para as quais a demanda de amor e o medo da morte inexistem como questões cruciais. Para elas, um outro sofrimento está posto.

Fábio chega agarrado às mãos do pai e da mãe e durante os primeiros meses do tratamento repete esta cena. Fábio nada fala, não me olha, mas me vê, o suficiente para desviar-se do meu olhar. Uma frase dita e repetida algumas vezes pela mãe denuncia o lugar desta criança na novela familiar. Ela diz: "... ou era cuidar dele, quando nasceu, ou do bar que meu pai deixou de herança... optei pelo bar!" Ao Fábio, restou a companhia de babás "incompetentes", cuidadosamente escolhidas pela mãe. O primeiro tempo do tratamento de Fábio foi marcado por sua insistência em manter na sala de atendimento os seus pais, que muito pouco falavam, mas que olhavam, surpresos, para as conquistas de Fábio. A colagem inicial ao corpo dos pais deslocou-se, depois de alguns meses de tratamento, para as mãos da analista e daí para outros objetos, surgindo em Fábio a possibilidade de olhar, de dirigir-se e de brincar com um outro.

Já Sandra entra na sala de atendimento, juntamente com outras crianças, e dirige-se ao espelho. Durante muito tempo, permanece aí, presa a algo que talvez nem saiba ser a própria imagem. A direção do trabalho com ela fez explodir esse espelho; hoje, algo nela já se sustenta como garantia de uma imagem própria que a represente. No início, diante do espelho, Sandra desenhava, com canetinhas, marcas em seu rosto; hoje, as mesmas marcas são feitas em uma figura humana esboçada em folhas de papel, que ela faz questão de pendurar na parede para que outros (a ) vejam.

Cátia, outra criança, entra na sala de atendimento acompanhada por seus pais, que muito pouco podem dizer sobre ela. Sabem, os pais, que na vida de Cátia há um antes e um depois da crise: aos oito anos, Cátia deixou de falar, de olhar, de se dirigir ao outro, deixou de querer conhecer e de aprender. Os pais trazem uma fita de vídeo e pedem para que a analista veja como Cátia era antes da crise; nesse momento do tratamento, a história de Cátia é uma história sem palavras para seus pais, quando a imagem de um tempo anterior vem no lugar.

Estas são três cenas recortadas de entrevistas ocorridas na PréEscola Terapêutica Lugar de Vida, instituição que recebe para tratamento crianças autistas, psicóticas e neuróticas graves. Há, nesses trechos, inúmeros elementos que merecem leitura aprofundada; porém, para esta apresentação, pensei em problematizar a clínica psicanalítica possível com crianças gravemente afetadas para, a partir daí, tangenciar o tema central dessa discussão, ou seja, a constituição do sujeito psíquico.

A clínica psicanalítica com crianças coloca-nos diante de alguns nós teóricos, uma vez que a Psicanálise foi concebida por Freud, 
como sabemos, a partir da escuta de pacientes neuróticos adultos. Neste momento e até onde Freud pôde tecer a sua teia de idéias sobre o psiquismo humano, ele não previra a utilização de suas descobertas no confronto direto com o sujeito criança; em sua obra prevalecem hipóteses para o emaranhado do infantil do sujeito. A intervenção psicanalítica junto à criança tem seu avanço com Melanie Klein, com Winnicott, com Françoise Dolto e tantos outros psicanalistas que bravamente produziram, e eu diria "provocaram", ajustes em relação à técnica da escuta analítica. No entanto, questões fundamentais, e ainda problemáticas, permeiam o trabalho com crianças. De quem tratamos? Qual o lugar dos pais neste tratamento? Qual a abrangência do campo transferencial? Como entender a associação livre com crianças? Como se interpreta nesta clínica? Quais os recursos técnicos para oferecer?, e tantas outras indagações.

Esta clínica complica-se ainda mais quando a criança que temos à frente é uma criança estranha, excluída do discurso social, como são as crianças autistas e algumas crianças psicóticas. Um primeiro esforço do analista que se implica no tratamento destas crianças é o de incluí-las no próprio discurso analítico, o que significa rever não só a teoria, como também criar atos clínicos que disponham tais crianças em diferentes relações com o outro, que não a relação de exclusão. Neste sentido, podemos pensar que a intervenção junto às 
crianças gravemente comprometidas inicia-se com a montagem de certos dispositivos institucionais que possam dar conta do estranho e às vezes do sinistro desta clínica. É o caso do C.P.P.L., uma clínica de vanguarda no país; dos hospitais-dia; do Centro Dra. Lydia Coriat, de Buenos Aires e de Porto Alegre; e mais recentemente do Lugar de Vida, cuja montagem e enquadre das atividades são reconhecidas pela equipe como uma intervenção terapêutica. Cristina Kupfer, psicanalista que coordena o trabalho do Lugar de Vida, no texto "As Instituições e a Psicanálise", - e eu diria que no dia-a-dia da instituição -, sustenta que a instalação do discurso analítico em uma instituição de tratamento de psicóticos é garantida não só na relação direta com os pacientes mas, principalmente, nas leituras dos acontecimentos feitas pelos profissionais da equipe (Kupfer, 1995). E sobre a natureza de uma instituição que trata psicóticos, Jerusalinsky (1993) adverte-nos para a importância de que tal instituição não tenha nenhuma certeza; ao contrário, que tenha uma profunda dúvida acerca de sua adequação ao fim a que se propõe, para que sua intervenção terapêutica não se cristalize em um método. Para ele, as intervenções desta instituição devem estar sujeitas às vicissitudes que cada criança lhe apresente. No Lugar de Vida, significantes como imprevisto e improviso têm circulado entre os profissionais da equipe, na tentativa de dizer sobre os atos analíticos que ali se produzem e que parecem intervir no rumo do que muitas vezes é da ordem do não-dito, como são as estereotipias na clínica do autismo e a agitação motora na clínica das psicoses.

Quando os pais de uma criança buscam tratamento, podemos reconhecer que um circuito de sofrimento está em jogo; é neste terreno que iremos intervir, uma vez que o sofrimento é uma das formas da demanda. Nas cenas apresentadas dos tratamentos de Fábio, Sandra e Cátia podemos reconhecer diferentes manifestações do sofrimento, ora localizadas nos pais, ora nas próprias crianças. Em conferência em São Paulo no ano passado, Levin (1995), psicanalista e psicomotricista do Centro Dra. Lydia Coriat, de Buenos Aires, disse-nos que "a responsabilidade mais ampla de um profissional que trabalha com criança é a de não retroceder ante o seu sofrimento, seja de qual ordem for esse sofrimento"; para ele, há sempre algo a fazer, uma vez que considera a impossibilidade de modelos para intervenção junto à criança. Garbarz (1995), também psicomotricista do Centro Dra. Lydia Coriat, contando-nos sobre a sua experiência clínica de vinte e cinco anos com crianças, afirmou-nos que "o sofrimento de quem vem consultar-nos já diz de como intervir nele". Estes são depoimentos importantes que me fazem pensar que, apesar do difícil empreendimento que é tratar uma criança, não podemos recuar. 
Talvez a função fundamental do analista frente a uma criança seja a de supor aí um sujeito: um sujeito capaz de amar e de trabalhar, como nos ensinou Freud nos primeiros tempos da Psicanálise. E entre o amor e o trabalho uma infinidade de outras conquistas podem se enlaçar. Estamos falando, então, do campo de desejo, e estamos, portanto, no território da ética psicanalítica, o que nos alivia em relação às diferenças entre a clínica com adultos e com crianças.

Já supondo a possibilidade de intervenção analítica no sofrimento de uma criança e de seus pais, podemos nos perguntar acerca do sujeito. É exatamente a partir das vicissitudes que uma criança apresenta, vicissitudes que a fazem ser levada a um estranho, um não-familiar - a um médico ou a um psicanalista -, que podemos nos questionar sobre o caminho da construção do sujeito psíquico.

É comum encontrarmos entre os psicanalistas discussões acerca da oposição entre a estruturação psíquica e o desenvolvimento de uma criança. Tenho pensado ser esta oposição uma questão mal colocada do ponto de vista da ação do psicanalista: se o ato analítico tem efeitos sobre o sujeito psíquico, muito pouco podem nos interessar os limites do corpo deste sujeito, uma vez que é de outro estatuto do corpo que falamos. Porém, só temos um sujeito psíquico, no qual podemos intervir, se este estiver assentado num corpo. Temos, então, que relativizar os limites do orgânico sobre o psíquico na constituição subjetiva. $\mathrm{O}$ trabalho com crianças coloca-nos neste impasse: olhar para um corpo em desenvolvimento e supor que ali um sujeito psíquico estrutura-se. Um analista, quando olha para uma criança, olha para sua história e, dessa forma, inclui o corpo numa dimensão simbólica e não puramente orgânica. A discussão que tem de um lado o desenvolvimento orgânico de uma criança e de outro a sua estruturação psíquica só faz sentido como limite de campos teóricos sobre a infância e não sobre uma criança, de fato. Esta discussão tem conseqüências clínicas importantes.

Afinal, na clínica psicanalítica de que sujeito tratamos? Temos aqui uma questão fundamental.

Em sua obra, Lacan sustenta ser impossível abordar de frente o sujeito da Psicanálise; ele considera o sujeito como resultado de uma construção. Na mesma direção, Miller (1988) afirma que "é a ética da Psicanálise que constitui, na experiência, o sujeito". Portanto, é a centenária clínica psicanalítica que nos apóia na sustentação de que, operativamente, o sujeito existe pelos efeitos de linguagem que sofre. Lacan e Miller falam do sujeito do inconsciente, fruto da situação analítica e do saber psicanalítico. Porém, a própria teoria psicanalítica nos fornece elementos para cogitar 
acerca da constituição do sujeito psíquico a partir da clínica com crianças.

Eu arriscaria dizer que o sujeito psíquico advém de uma operação que vai do corpo à imagem, da imagem à palavra e da palavra ao desejo. É uma operação que se inicia antes mesmo de um bebê nascer; inicia-se na história de seus pais, que por sua vez inicia-se nas histórias de outros pares parentais, e assim por diante. A constituição do sujeito, em certa medida, é a ficção própria que um sujeito pode fazer a partir da história dos homens; neste sentido, ela pode ser entendida como a construção de uma metáfora que represente ao sujeito.

Nesta perspectiva, uma criança que nasce é um sujeito em potencial. A operação metafórica antes suposta - do corpo à imagem à palavra e ao desejo - pede a participação de "agentes" junto a um bebê, "agentes" que operem a função materna e a função paterna, como garantia de uma posterior diferenciação. Este primeiro tempo da operação parte da noção básica freudiana de que o sujeito humano constitui-se na construção e na diferenciação dos seus objetos; inicialmente, o circuito pulsional coloca o pequeno ser em contato com o que já não o é, para depois reconhecer o que pode representá-lo. Um longo e delicado caminho tem, então, o filhote humano até a sua subjetivação.

$O$ bebê, que nada sabe de si, para aceder a uma condição de ser falante, carece de marcas que fundem nele uma história: a mãe, ao pegar seu bebê, ao trocá-lo, ao amamentá-lo, ao dirigir-lhe palavras, faz muito mais que pegar, tocar, falar; junto com os atos que promove no corpo da criança, a mãe testemunha a participação dela no mundo dos homens, ela oferece a linguagem, oferece o que Lacan denominou "tesouro de significantes". Jerusalinsky (1996) diz que "a mãe é a grande instaladora de buracos no bebê", é ela quem produz no bebê as bordas de seu corpo, os olhos, a boca, o ânus, os ouvidos, é ela quem marca, já no corpo da criança, a falta. Para Levin (1995), a função materna passa sempre pelo toque, em que o "intocável do toque é o desejo".

À posição materna cabe ainda a tarefa de duvidar de seu saber sobre o bebê que tem à frente. Ao duvidar, uma mãe abre portas a um outro - o pai da criança ou alguém na posição paterna -, para que este lhe diga como promover a completa descontinuidade do seu bebê. A entrada do terceiro é que marca, de fato, a possibilidade do advir de um sujeito psíquico, pois com ele a cumplicidade estabelecida entre a mãe e o bebê sofre um rearranjo. Lembremos que as personagens desta trama estão igualmente submetidas às leis da linguagem que, estruturalmente, introduzem a noção da impossibilidade do todo, da impossibilidade da completude.

$\mathrm{Na}$ letra freudiana encontramos hipóteses sobre a constituição 
subjetiva. Destaco dois momentos de sua elaboração: o primeiro em "Sobre o Narcisismo: uma introdução", artigo em que Freud (1914) defende a existência de um narcisismo primário em todos, caracterizando-o como o tempo em que a libido do bebê está voltada para o próprio corpo; outro momento está em "O Ego e o Id", no qual Freud (1923) é categórico ao dizer que "o ego é, primeiramente, um ego corporal, não uma superfície, mas a projeção de uma superficie".

A partir de Freud, Lacan produz avanços teóricos ao propor a noção do Estádio do Espelho como momento inaugural do sujeito psíquico. O tempo do Estádio do Espelho é marcado pela possibilidade de o bebê identificar-se com uma imagem, imagem esta primeiramente sustentada pela forma total do corpo como uma exterioridade, ou, como diz Lacan (1949), "como uma Gestalt, uma forma mais constituinte que constituída". O resultado do Estádio do Espelho é uma antecipação do eu, precipitada pela armadilha de identificação espacial, que faz com que uma imagem retalhada do corpo tenha uma forma ortopédica de sua totalidade no espelho.

De acordo com esta articulação, a imagem própria advém do outro e, se seguirmos os rastros do desejo, também o desejo próprio origina-se no desejo do Outro. No seminário sobre as psicoses, Lacan (1955-56) aponta para a tendência do eu humano de estar, na sua origem, muito mais próximo da forma do outro que da sua própria. Ele diz: "O sujeito humano desejante constitui-se em torno de um centro que é o outro, na medida em que ele lhe dá a sua unidade, e o primeiro acesso que ele tem do objeto é o do objeto enquanto objeto do desejo do outro".

Para aceder à palavra, uma criança deve renunciar ao corpo enquanto objeto material que a represente, buscando outra forma de apresentar-se para o outro. Estamos aqui na dimensão simbólica do sujeito, aquela que garante, por exemplo, que o nome da criança seja o significante, por excelência, que a represente.

As crianças que são trazidas para tratamento nos mostram, de variadas formas, impasses na constituição psíquica. Algo falhou, em território familiar, que precisa ser retomado, por um estrangeiro, posicionado analista, a partir do olhar, da imagem, da palavra e do desejo. Temos, então, uma situação artificial, mas profundamente importante para uma retomada, pela criança, de sua constituição psíquica. Jerusalinsky (1994) sustenta que a obrigação do analista de crianças é exatamente a de "olhar para o que nela não está constituído".

Um analista, para olhar, deve saber de onde olha, para cogitar sobre o que vê. Diferente da clínica com neuróticos que associam livremente deitados no divã - sabemos que nem tão livremente assim -, o analista na clínica com crianças, - e mais ainda, com cri- 
anças profundamente marcadas ou sem marcas, o que parece ser mais trágico -, o analista deve construir referenciais teóricos que lhe permitam olhar para o sujeito na criança. Esta é a garantia e o apoio de que seus atos clínicos não se perderão no toque que uma criança lhe faz sem mesmo saber que toca um outro. Digo isto, porque cada um que se dispõe a tratar de crianças sabe que o seu corpo ocupa uma posição especial nesta clínica, pois presta-se e empresta-se, a todo momento, às demarcações imprescindíveis à criança devir sujeito.

Mas o que caracteriza e diferencia a clínica psicanalítica é a palavra: aí está todo o potencial para a mudança de posição de uma criança ou de seus pais. A responsabilidade pelo bem dizer é do analista; sustentada pela transferência, sua palavra tem poder transformador. É pela palavra que o analista faz surgir um sujeito. A partir de uma especial posição especular, o analista, com seu olhar e sua palavra, recorta traços fundamentais na criança, traços para os quais o fantasma de cada um dos pais a impede de olhar, justamente porque os implica, inconsciente e subjetivamente, nos problemas que a criança apresenta.

E sobre o desejo, o que podemos dizer?

A partir da clínica psicanalítica, sabemos que o desejo pulsa no sujeito. No entanto, só podemos falar em desejo se supusermos a existência de um sujeito estruturado a partir da falta fundamental. Nesta perspectiva, o desejo advém do reconhecimento da falta. As 
hipóteses sobre a constituição do sujeito - entre elas, a noção de que, inicialmente, a criança está amarrada ao desejo do Outro -, bem como o jogo transferencial posto na clínica com crianças, sugere-nos que nesta clínica questionemos acerca do desejo não só em relação à criança e aos seus pais, mas também em relação ao próprio analista. Porém, não é na clínica que o analista sabe de seu desejo; eu penso que é somente na experiência da análise pessoal que um analista pode dar verdadeiro sentido à questão do desejo: aí ele pode estar sujeito às surpresas do desejo próprio. Neste sentido, também o trabalho de supervisão clínica pode colocar o analista frente ao desejo; nesta situação ele ocupa lugar daquele que não sabe e, por isso, demanda.

Para finalizar, gostaria de retornar às crianças cujas histórias me orientaram na preparação deste trabalho. Quando iniciei a escrita deste texto, tinha a intenção de trabalhar clinicamente os recortes selecionados. Percebi, durante a escrita, que as cenas trazidas me foram úteis para sustentar uma construção teórica sobre o que determinei como tempos da constituição do sujeito, - tempos vistos pelo viés da clínica psicanalítica -, ou sejam, o olhar, a imagem, a palavra e o desejo. Constatei, no après-coup, que as cenas selecionadas das histórias de cada criança foram os pilares da minha articulação: em Fábio, a questão do olhar e do corpo; em Sandra, a questão da imagem; e em Cátia, o adormecimento da palavra. Sobre o desejo, transportei-me também para o campo da análise pessoal do analista, talvez porque nestas crianças um outro tempo esteja em jogo.

A busca por uma compreensão teórica sobre a constituição subjetiva de cada uma das crianças foi um exercício que certamente enriqueceu e modificou as minhas hipóteses sobre elas. Mais ainda, penso que poder dizer sobre este trabalho já é uma garantia de que retorno à escuta das histórias destas crianças a partir de um outro lugar. Neste momento, opto, então, por silenciarme sobre elas!

\section{REFERÊNCIAS BIBLIOGRÁ FICAS}

FREUD, S. (1923). O ego e o id. In: Edição standard brasileira das obras completas de Sigmund Freud. Rio de Janeiro, Imago, 1974. v.19.

- FREUD, S. (1914). Sobre o narcisismo: uma introdução. In: Edição standard brasileira das obras completas de Sigmund Freud. Rio de Janeiro, Imago, 1974, v.14.

- GARBARZ, J. Abordagem interdisciplinar dos problemas de desenvolvimento infantil. São Paulo, 1996. (Curso realizado no Instituto de Psicologia da Universidade de São Paulo).

- JERUSALINSKY, A. Abordagem interdisciplinar dos problemas de desenvolvimento 
infantil. Sào Paulo, 1996. (Curso realizado no Instituto de Psicologia da Universidade de São Paulo).

- JERUSALINSKY, A. La educación, es terapéutica?: acerca de tres juegos constituyentes del sujeto. In: Escritos de la infancia. Buenos Aires, Fundación para el Estudio de los Problemas de la Infancia, 1994. v.4.

- JERUSALINSKY, A. Psicose e autismo na infância: uma questão de linguagem. Revista Psicose, Porto Alegre, 1993.

ם KUPFER, M.C.M. As instituições e a psicanálise. São Paulo, 1995. (Trabalho apresentado no Seminário de Crianças da Escola Brasileira de Psicanálise, Seção São Paulo).

- LACAN, J. (1949). El estadio del espejo como formador de la función de yo (je) tal como se nos revela en la experiencia psicoanalítica. In: Escritos 1. Buenos Aires, Siglo Veintiuno, 1994.

- LACAN, J.(1955-56) Seminário 3: As psicoses. Rio de Janeiro, Zahar, 1992.

- LEVIN, E. Abordage interdisciplinario de los problemas del desarollo infantil. Buenos Aires, 1995. (Curso realizado no Centro Dra. Lydia Coriat).

- LEVIN, E. A psicanálise e a interdisciplina na infância com problemas. Sào Paulo, 1995. (Conferência apresentada no Instituto de Psicologia da Universidade de Sào Paulo).

- MILLER, J.A. Diagnóstico psicanalítico e localização subjetiva: segunda conferência do Seminário do Campo Freudiano. Falo: Revista Brasileira do Campo Freudiano, n.2, jan./jun. 1988.

\section{NOTAS}

1 Trabalho apresentado no III Encontro Psicanalítico - Espaço e tempo em Psicanálise: questões teóricas e clínicas, promovido pelo C.P.P.L. ( Centro de Pesquisas em Psicanálise e Linguagem ), em Recife, entre os dias 30 de agosto e 01 de setembro de 1996, com auxílio financeiro da FAPESP. 